\title{
Comparison of postoperative skeletal stability of maxillary segments after Le Fort I osteotomy, using patient-specific implant versus mini-plate fixation
}

\author{
Karoliina V.M. Kotaniemi a, c, *, Arja Heliövaara ${ }^{\text {b }}$, Miika Kotaniemi ${ }^{\text {e }}$, Patricia Stoor ${ }^{\text {a }}$, \\ Junnu Leikola ${ }^{\mathrm{b}}$, Tuula Palotie ${ }^{\mathrm{a}, \mathrm{c}, 1}$, Juho Suojanen ${ }^{\mathrm{b}, \mathrm{d}, 1}$ \\ ${ }^{a}$ Department of Oral and Maxillofacial Diseases, Head and Neck Center, Helsinki University Hospital, Finland \\ ${ }^{\mathrm{b}}$ Cleft Palate and Craniofacial Center, Department of Plastic Surgery, Helsinki University Hospital, Finland \\ c Orthodontics, Department of Oral and Maxillofacial Diseases, Clinicum, Faculty of Medicine, University of Helsinki, Finland \\ d Päijät-Häme Joint Authority for Health and Wellbeing, Department of Oral and Maxillo-Facial Surgery, Lahti, Finland \\ e Department of Built Environment, Aalto University, Finland
}

\section{A R T I C L E I N F O}

\section{Article history:}

Paper received 29 August 2018

Accepted 15 April 2019

Available online 27 April 2019

\section{Keywords:}

Le Fort I osteotomy

Orthognathic surgery

Patient-specific implant

Relapse

3D

Stability

\begin{abstract}
A B S T R A C T
Background: Three-dimensionally (3D) designed osteotomies and customised osteosynthesis are rapidly becoming standard in maxillofacial reconstructive and deformity surgery. Patient-specific implants (PSIs) have been in use for a few years in orthognathic surgery as well. In Le Fort I osteotomy, wafer-free fixation of the maxillary segment can be performed by individually manufactured cutting and drill guides together with PSIs.

Aim: This retrospective study was performed to compare the postoperative skeletal stability of the maxillary segment fixed by patient-specific implants versus mini-plates after Le Fort I osteotomy.

Patients: Fifty-one patients were divided into subgroups according to the fixation method and the advancement of the sub-spinal point. The postoperative skeletal stability of the maxillary segment was evaluated from lateral cephalometric radiographs one year postoperatively.

Results: No statistically significant differences were found between the postoperative skeletal stability of the PSI and mini-plate fixed maxillae. Prospective studies, possibly with 3D fusion analysis, are warranted to confirm the results.

Conclusion: The choice between the two fixation methods does not seem to affect the postoperative skeletal stability of the maxillary segments.
\end{abstract}

๑) 2019 European Association for Cranio-Maxillo-Facial Surgery. Published by Elsevier Ltd. All rights reserved.

\section{Introduction}

The use of three-dimensional (3D) design is rapidly becoming a common practise in orthognathic surgery. The benefits are clear in two-jaw surgery and in complex asymmetry cases in both planning and performing the surgery. Individually designed and manufactured surgical drill and cutting guides as well as patient-specific implants (PSI) for osteosynthesis are now available for reasonable

\footnotetext{
* Corresponding author. Department of Oral and Maxillofacial Diseases, Helsinki University Central Hospital, P.O. Box 263, 00029 HUS, Finland.

E-mail address: karoliina.kotaniemi@helsinki.fi (K.V.M. Kotaniemi).

1 These authors contributed equally to this project.
}

costs and within a short space of time. The development of 3Ddesigned implants has been fast.

Change from crude modifications of conventional mini-plates to individualised implants became possible when computer-aided design and manufacturing (CAD/CAM), including milling and printing techniques, started to develop (Gander et al., 2015; Mazzoni et al., 2015; Suojanen et al., 2016). Individually milled implants, combined with the use of drill guides also makes waferfree fixation of the maxillary segment possible, and ideal fitting of the osteosynthesis material is passive and tension-free. Whether this leads to better postoperative skeletal stability remains to be investigated. The use of PSIs for wafer-free fixation and osteosynthesis after Le Fort I osteotomy has proven reliable and accurate (Suojanen et al., 2016; Heufelder et al., 2017). According to the literature, the stability of the maxillary segments after Le Fort I 
osteotomy has been debated, especially in cases when the maxillary segments were moved counter-clockwise (Ohba et al., 2015). However, the treatment results with mini-plates for semi-rigid osteosynthesis have markedly improved results and stability compared to wire osteosynthesis (Larsen et al., 1989; Reyneke et al., 2007). Differences in the susceptibility to postoperative relapse in cases treated with mini-plate versus PSI fixation have not been reported.

The aim of this study was to compare the postoperative skeletal stability of the new position of the maxillary segment fixed either with PSIs or conventional mini-plates after Le Fort I osteotomy and repositioning, using clinical and cephalometric data after 9-34 months follow-up.

\section{Material and methods}

\subsection{Patients}

This retrospective study investigated the clinical and cephalometric records of 51 patients treated with Le Fort I osteotomy in Helsinki University Hospital (HUH), Helsinki, Finland. Inclusion criteria for the study were as follows: (1) Le Fort I maxillary surgery, with or without simultaneous mandibular osteotomy (bilateral sagittal split osteotomy [BSSO]); (2) availability of preoperative (T1), immediate postoperative (T2) and follow-up (T3, nine months to 34 months postoperatively) cephalometric radiographs; (3) availability of patient data records.

The patients were divided into two groups according to the method of maxillary fixation. The first study group (Group A) was a retrospective cohort of PSI-fixed maxillae that was collected between December 2013 and November 2015. This patient series was also used in our earlier studies (Suojanen et al., 2016; Suojanen et al., 2016). A few patients (patient nos 3, 4, 11 and 32 in the study by Suojanen et al., 2016, and patient nos. 3 and 11 in the study by Suojanen et al., 2018, respectively) were excluded from the present study due to lacking follow-up radiographs, and one patient (no 28 in the study published 2016 and no 18 in the study published 2018, respectively) due to a genetic disorder (Treacher Collins).

The second group (Group B) of mini-plate fixed maxillae were collected between September 2011 and November 2013. This cohort has not been published fully earlier. Part of the series (operations November 1, 2011 to November 30, 2013) was published similarly earlier as presented with the PSI group (Suojanen et al., 2018). Due to lacking follow-up radiographs, we expanded the cohort period to achieve a matching number of patients for the analysis.

More specific information about the groups is presented in Table 1. Anamnestic and clinical findings were recorded at the beginning of the treatment. Table A.1 in Appendix A presents more detailed data on patients.

All the patients were treated orthodontically with fixed appliances as part of the orthognathic surgery treatment at HUH. During postoperative orthodontics, intermaxillary elastics were used. After the postoperative orthodontics, the retention period started, and the patients wore a removable retention plate $24 \mathrm{~h}(\mathrm{~h}) /$ day for six to nine months and then during night time for 1.5 years. In addition, permanent retention wires were placed lingually to lower incisors and canines and often palatinally to upper incisors. During the

Table 1

Patients.

\begin{tabular}{lll}
\hline & Group A & Group B \\
\hline Number of patients & 27 (16 males, & $24(13$ males, \\
& 11 females) & 11 females) \\
Mean (range) age (years) & $29(19-48)$ & $29(19-52)$ \\
\hline
\end{tabular}

retention period, the patients were checked at least every six months, and good stability of the occlusion and incisal inclination was detected.

\subsection{Surgical methods}

Fifty-one patients underwent Le Fort I surgery, which was performed sub-spinally with a similar surgical protocol regardless of the fixation system used. In sub-spinal osteotomy (Mommaerts et al., 1997), the bony nasal spine is separated from the maxillary segment with a saw, after which the nasal mucosa and septal cartilage are freed from the hard palate together with the bony nasal spine. When Le Fort I osteotomy is performed sub-spinally, the osteotomy line is approximately at the same level as the subspinal point (point A), in which case, point $A$ is transferred together with the maxillary segment.

The operations were performed by four senior surgeons accompanied by junior surgeons. The differences in the results between the surgeons were not investigated in this study.

Twenty-seven patients received bone graft to the Le Fort I osteotomy line, of whom 14 belonged to Group A and 13 to Group B. Nine of the Le Fort I osteotomies were performed with segmentation of the maxillary segments into two pieces and two into three pieces. A simultaneous BSSO (Epker, 1977) was performed in 24 patients. Two patients underwent Le Fort I osteotomy and BSSO at different dates due to an open bite, one noticed immediately postoperatively and the other one during the routine postoperative control. Two patients underwent reoperation with a second Le Fort I osteotomy. One of these patients was initially treated with a bimaxillary surgery, and the open bite was noticed immediately postoperatively. The other one was initially operated with Le Fort I osteotomy and underwent reoperation due to an unsatisfactory bite immediately postoperatively. All the patients who underwent reoperation belonged to the mini-plate group (Group $\mathrm{B}$ ). The immediate postoperative cephalometric radiograph taken after the reoperation was used as the immediate postoperative cephalometric radiograph (T2) for all the patients who underwent reoperation, because the surgical treatment was finished only after reoperation.

Group A received custom-made, 3D-designed, patient-specific fixation. The skeletal structures of the face of each patient were preoperatively imaged by computed tomography (CT) and transformed into a 3D image. The surgery and PSIs were planned virtually with a 3D program (Planmeca ProModel system, Planmeca Ltd, Helsinki, Finland). The PSIs were manufactured using computeraided design and manufacturing (CAD/CAM) technology (Planmeca Ltd, Helsinki, Finland) according to the surgical plan. The general form of PSI was identical in all patients as presented earlier (Suojanen et al., 2016). All patients had two PSIs, where the cranial and tooth-bearing segments were interconnected with two bridging bars in zygomatic buttress and aperture piriformis areas. The PSI frame width was $2 \mathrm{~mm}$ and the thickness was $0.8 \mathrm{~mm}$; it was milled from grade 23 titanium monoblocks. In segmented osteotomies, all segments contained at least two screw holes per side.

Group B underwent surgery with conventional wafers and a mini-plate fixation. The mini-plates (DePuy Synthes, Matrix Orthognathic, Raynham, MA, USA) were bent on-site during the surgery. L-shaped, $0.8 \mathrm{~mm}$ thick Matrix Orthognathic plates (DePuy Synthes, Matrix Orthognathic, Raynham, MA, USA) were placed in the zygomatic buttress and the piriform aperture. In segmented osteotomies, the segments were also bridged with $0.6 \mathrm{~mm}$ or $0.8 \mathrm{~mm}$ straight Matrix Orthognathic mini-plates with at least two screws on each side of the segment.

In both groups, monocortical Synthes Matrix Orthognathic screws $6-8 \mathrm{~mm}$ in length and $1.85 \mathrm{~mm}$ in diameter (DePuy 
Synthes, Matrix Orthognathic, Raynham, MA, USA) were used primarily for plate/implant fixation. In the case of a hole failure of the primary screw, $2.1 \mathrm{~mm}$ emergency screws were used routinely.

Postoperative cephalometric and panoramic radiographs were taken one day postoperatively of all the patients in this study. According to the clinic's normal treatment protocol, follow-up radiographs were taken one year postoperatively, combined with the final surgical check-up. The purpose of the follow-up radiographs was to evaluate the ossification of the operation site and the stability of the correction of the malocclusion radiologically.

\subsection{Cephalometric analysis}

The postoperative skeletal stability of the maxillary segments was evaluated from the standardised lateral cephalometric radiographs taken with the Frankfurt plane positioned horizontally. Radiographs taken at three time points were used: preoperative (T1, on average 4.5 months prior to the surgery, range 1-26 months), immediate postoperative (T2, one day after the surgery) and follow-up radiographs (T3, on average 14.5 months postoperatively, range 9-34 months).

The cephalometric tracing was digitised using the Dolphin Imaging 11.95 Premium program (Patterson Dental Supply, Inc., Minnesota, USA) with conventional cephalometric analysis. To evaluate the amount of anteroposterior and vertical surgical transfer of the maxillary segments, the immediately postoperative radiograph was superimposed over the preoperative cephalometric radiograph (Fig. 1A). Evaluation of the skeletal stability was performed by superimposing the follow-up radiograph over the immediately postoperative radiograph (Fig. 1B). To ensure that the cephalometric points used for the measurements were placed at correct points, sella-nasion and porion-orbitale lines were first adjusted to correspond to each other in each radiograph of the particular patient.

The skeletal stability was investigated by determining the relapse of the maxillary segments using the best available skeletal and dental points. The relapse was evaluated both in anteroposterior and vertical dimensions.

The anteroposterior points used in the determination of the relapse were (1) sub-spinal point (A point); (2) posterior nasal spine (PNS); (3) upper central incisal tip (U tip); (4) the angle between sella, nasion, and A point (SNA angle). The vertical points used in the determination of the relapse were (1) U tip and (2) PNS (Fig. 2).

The $U$ tip was used for the evaluation both in anteroposterior and vertical dimensions. Although $U$ tip is a dental point, the inclinations of the upper incisors are decided and achieved in our treatment protocol at the preoperative orthodontic treatment and the changes of the incisor inclinations during postoperative orthodontics are very minor if any. The reliability of the $U$ tip point was ensured by superimposing the immediately postoperative and follow-up radiographs in line with the maxillae and checking whether the inclination of the upper incisors had remained unchanged during the postoperative orthodontic treatment. The inclination of the upper incisors was shown to have remained very stable; thus, the U tip point was included in the evaluation.

The patient data was further divided into subgroups according to the original anteroposterior movement of the A point during the surgery:

1. Forward movement of the A point less than $2 \mathrm{~mm}$, where the main purpose of the surgery was to rotate the maxillary segments vertically either clockwise or counter-clockwise to correct the malocclusion

2. Forward movement of the A point more than $2 \mathrm{~mm}$

Subgroup 2 was further divided into two smaller subgroups to see whether there was a statistically significant difference in the stability, depending on the length of the forward transfer:

2.1) Forward movement of the A point $2-5 \mathrm{~mm}$

2.2) Forward movement of the A point more than $5 \mathrm{~mm}$
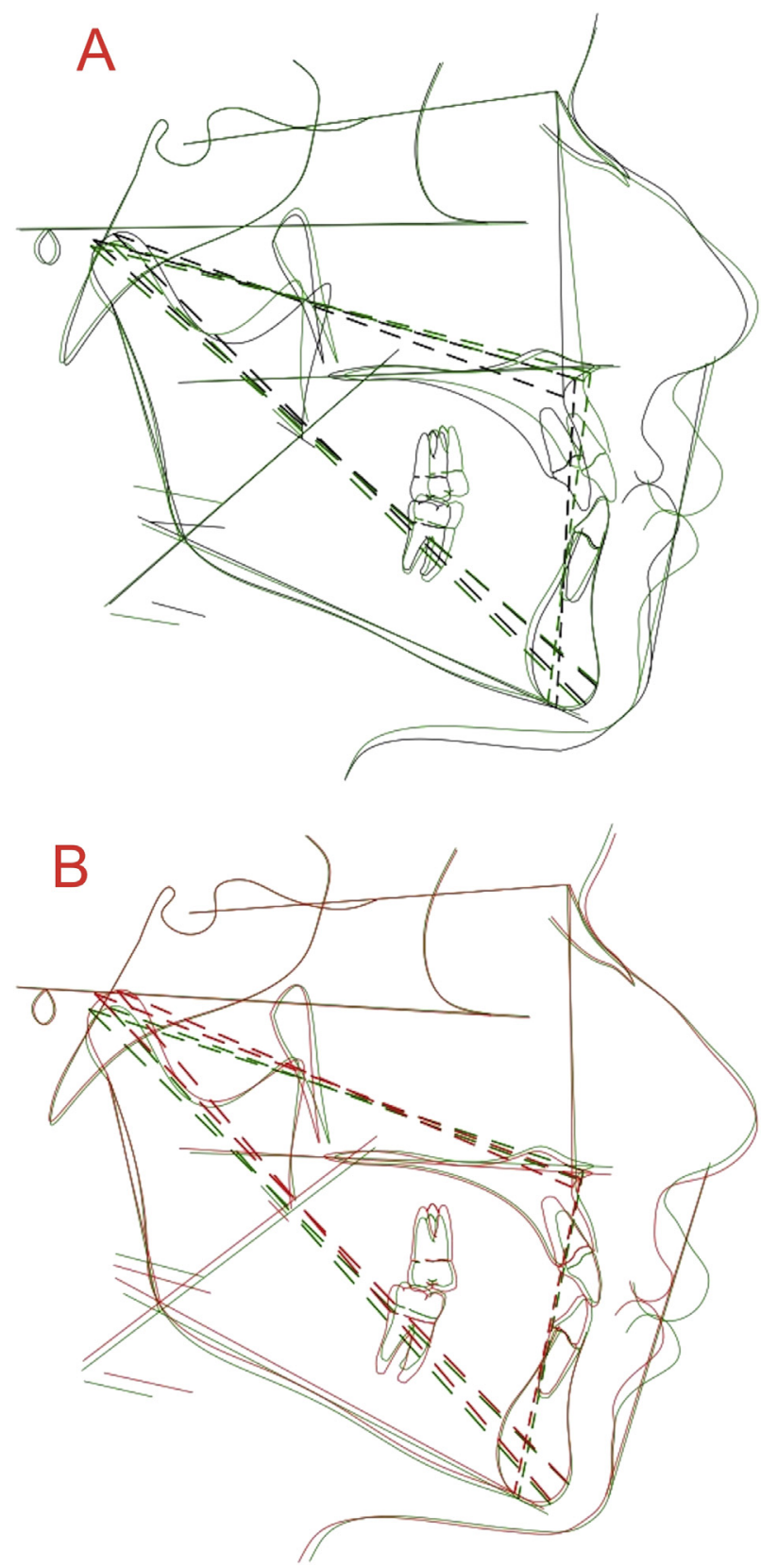

Fig. 1. Superimposition of the cephalometric radiographs: (A) preoperative (black) and immediate postoperative (green); (B) immediate postoperative (green) and follow-up (red). 


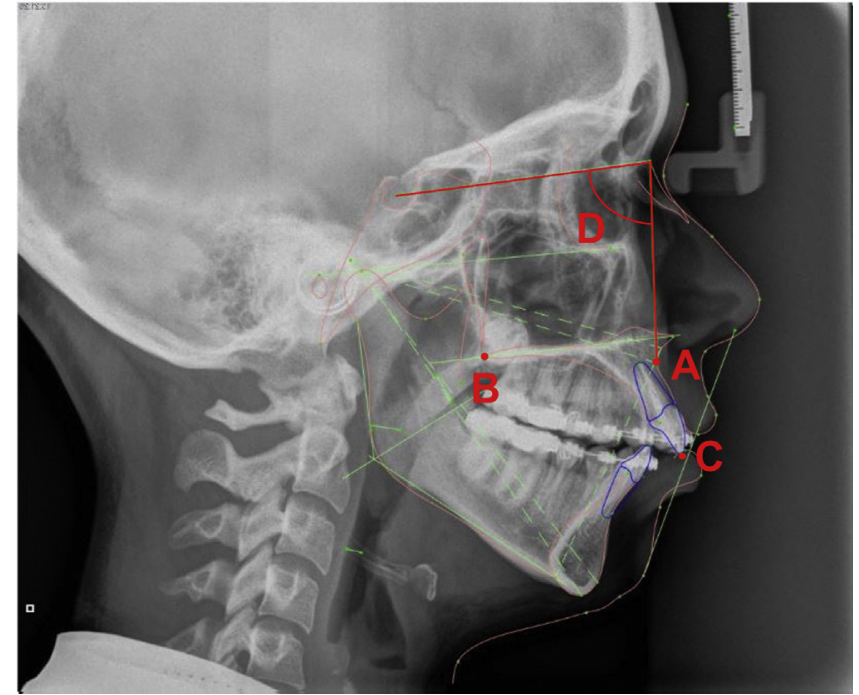

Fig. 2. Cephalometric points and lines used in the study: (A) A point; (B) PNS; (C) U tip; (D) SNA angle.

Patient data of the different subgroups is presented in Tables 2 and 3.

\subsection{Statistical analysis}

The $t$-test and Mann-Whitney $U$ test were used for normally distributed and non-normally distributed variables, respectively, to examine whether the relapse of the points of interest differed significantly from each other in the two study groups (Group A and Group B). The patient data was further divided into smaller subgroups 1, 2, 2.1 and 2.2 described earlier, which were tested with the applicable $t$-test or the Mann-Whitney U test as well. Multiple testing corrections were made for all the p-values by various methods.

A further analysis was performed for the dependent variables, with the smallest p-values in the $t$-test or Mann-Whitney U tests. A regression analysis was conducted, taking into account the following independent variables: age at the operation date, sex, rheumatoid disease, smoking, open bite as a diagnosis, use of bone graft during the operation and the vertical direction of the movement of the maxillary segments during the operation. The residuals were tested and concluded homoscedastic and normally distributed.

In all statistical analyses, values of $\mathrm{p} \leq 0.05$ were considered statistically significant.

For the statistical analysis, biostatistics experts were consulted, and all the analyses were verified by them.

\subsection{Intra-rater reliability}

One observer (KK) performed the cephalometric tracing. Intraexaminer reliability was assessed by digitising twice 20 randomly selected radiographs, including radiographs from all the stages. The intra-class correlation coefficient (ICC) was used to calculate the error.

\subsection{Ethical permission}

The protocol of the retrospective study was approved by the Hospital District of Helsinki and Uusimaa (HUS/358/2018, §4). The study does not fulfil characteristics of a medical study according to the Medical Research Act and does not need ethical permission. Principles outlined in the Declaration of Helsinki were followed.

\section{Results}

\subsection{Clinical findings}

A total of 51 patients ( 24 males, 27 females) were included in the study. Group A (mean age 29 years, range 19-48 years) was a retrospective cohort of PSI-fixated maxillary segments and Group B (mean age 29 years, range 19-52 years) of mini-plate fixated maxillary segments. Patient-specific data on gender, age, orthodontic diagnosis, type of surgery and bone grafting are shown in Table A.1 in Appendix A. Clinical dental findings are shown in Table 4.

\subsection{Cephalometric results of surgery movements}

The mean forward transfer of the maxillary segments was $4.5 \mathrm{~mm}$ (range $0.0-10.0 \mathrm{~mm}, \mathrm{SD}=2$ ) in Group A and $4.9 \mathrm{~mm}$ (range $-1.0-10.0 \mathrm{~mm}, \mathrm{SD}=3.7$ ) in Group $\mathrm{B}$, respectively. The anterior impaction was on average $1.2 \mathrm{~mm}$ (range $-2.3-5.0 \mathrm{~mm}$, $S D$ 2.1) and the posterior impaction was $1.1 \mathrm{~mm}$ (range $-5.7-5.0 \mathrm{~mm}, \mathrm{SD} 2.4$ ) in Group A. For Group B, the respective values were $0.2 \mathrm{~mm}$ (range $-7.9-3.0 \mathrm{~mm}, \mathrm{SD} 2.4$ ) and $0.8 \mathrm{~mm}$ (range $-2.0-3.5 \mathrm{~mm}$, SD 1.4).

\subsection{Cephalometric results of stability}

No statistically significant differences were found between the stability of the studied groups, that is, PSI (Group A) vs. mini-plate (Group B) fixed, when comparing the two whole groups of patients (Table 5).

No statistically significant differences were found in subgroup 1 (forward movement of the A point less than $2 \mathrm{~mm}$ ), as shown in Table 6.

In addition, eliminating the very small forward transfers of the A point as a result of only rotating the maxillary segments (subgroup 1) and examining subgroup 2 (forward movement of the A point more than $2 \mathrm{~mm}$ ) yielded no statistically significant differences, as shown in Table 7.

However, examining subgroups 2.1 (forward movement of the A point $2-5 \mathrm{~mm}$ ) and 2.2 (forward movement of the A point more than $5 \mathrm{~mm}$ ), yielded a statistically significant difference in subgroup 2.1 in the relative relapse of the $U$ tip in the vertical

Table 2

Subgroups 1 and 2

\begin{tabular}{lll}
\hline & Subgroup 1 & Subgroup 2 \\
\hline Number of patients & 13 (7 males, 6 females) & $38(17$ males, 21 females) \\
Group A patients & $8(4$ males, 4 females $)$ & $19(7$ males, 12 females) \\
Group B patients & $5(3$ males, 2 females) & $19(10$ males, 9 females) \\
Mean (range) age (years) & $30(22-48)$ & $28(19-52)$ \\
Mean (range) age (years) of Group A & $32(23-48)$ & $27(19-45)$ \\
Mean (range) age (years) of Group B & $28(22-43)$ & $29(19-52)$ \\
\hline
\end{tabular}


Table 3

Subgroups 2.1 and 2.2

\begin{tabular}{lll}
\hline & Subgroup 2.1 & Subgroup 2.2 \\
\hline Number of patients & 21 (7 males, 14 females) & $17(10$ males, 7 females $)$ \\
Group A patients & 12 (4 males, 8 females) & $7(3$ males, 4 females) \\
Group B patients & $9(3$ males, 6 females) & $10(7$ males, 3 females) \\
Mean (range) age (years) & $28(19-48)$ & $28(21-52)$ \\
Mean (range) age (years) of Group A & $27(19-45)$ & $27(21-43)$ \\
Mean (range) age (years) of Group B & $28(19-48)$ & $29(21-52)$ \\
\hline
\end{tabular}

Table 4

Findings of the clinical dental examination of the patients at the beginning and end of the treatment.

\begin{tabular}{|c|c|c|c|c|}
\hline \multirow[t]{2}{*}{ Preoperatively } & \multicolumn{2}{|c|}{ Group A } & \multicolumn{2}{|c|}{ Group B } \\
\hline & Mean & Range & Mean & Range \\
\hline Maximum jaw opening (mm) & 48.0 & $30-62$ & 50.0 & $40-65$ \\
\hline Overjet $(\mathrm{mm})$ & 3.0 & $-3.0-14.0$ & 1.0 & $-9.0-15.0$ \\
\hline Overbite (mm) & -0.7 & $-6.0-6.0$ & -0.1 & $-4.0-3.5$ \\
\hline Lower facial height (LAFH/TAFH) (\%) & 55.5 & $51.4-60.8$ & 55.4 & $49.0-62.0$ \\
\hline Angle between sella-nasion plane and mandibular plane (MP-SN) $\left(^{\circ}\right)$ & 40.8 & $3.1-62.4$ & 36.3 & $17.5-48.9$ \\
\hline Angle between palatal plane and mandibular plane $(\mathrm{PL}-\mathrm{MP})\left(^{\circ}\right)$ & 34.4 & $-4.5-55.6$ & 29.7 & $16.9-42.7$ \\
\hline SNA $\left({ }^{\circ}\right)$ & 81.1 & $73.6-88.7$ & 81.4 & $64.4-87.5$ \\
\hline Upper incisal inclination $\mathrm{U} 1-\mathrm{SN}\left({ }^{\circ}\right)$ & 105.2 & $91.7-122.8$ & 105.3 & $93.5-124.6$ \\
\hline Upper Incisal inclination U1-PL $\left(^{\circ}\right)$ & 111.6 & $99.5-129.9$ & 111.9 & $97.0-131.5$ \\
\hline Lower incisal inclination $\mathrm{L} 1-\mathrm{MP}\left(^{\circ}\right)$ & 89.2 & $73.4-102.5$ & 90.1 & $76.1-107.0$ \\
\hline \multirow[t]{2}{*}{ At the end of treatment } & \multicolumn{2}{|c|}{ Group A } & \multicolumn{2}{|c|}{ Group B } \\
\hline & Mean & Range & Mean & Range \\
\hline Maximum jaw opening $(\mathrm{mm})$ at the beginning of retention & 46.0 & $23-62$ & 49.0 & $36-70$ \\
\hline Overjet (mm) at the beginning of retention & 2.4 & $1.0-5.0$ & 2.3 & $0.5-4.5$ \\
\hline Overbite $(\mathrm{mm})$ at the beginning of retention & 1.8 & $0.0-3.0$ & 1.7 & $-1.0-3.0$ \\
\hline Lower facial height (LAFH/TAFH) (\%) & 55.6 & $51.5-60.5$ & 55.3 & $50.2-60.2$ \\
\hline Angle between sella-nasion plane and mandibular plane $(\mathrm{MP}-\mathrm{SN})\left({ }^{\circ}\right)$ & 39.3 & $19.2-58.7$ & 35.9 & $19.2-51.2$ \\
\hline Angle between palatal plane and mandibular plane $(\mathrm{PL}-\mathrm{MP})\left({ }^{\circ}\right)$ & 32.8 & $6.7-53.6$ & 27.5 & $17.0-41.8$ \\
\hline SNA $\left({ }^{\circ}\right)$ & 84.2 & $74.9-94.9$ & 85.5 & $72.0-93.9$ \\
\hline Upper Incisal inclination $\mathrm{U} 1-\mathrm{SN}\left({ }^{\circ}\right)$ & 106.3 & $90.4-119.2$ & 105.5 & $90.5-132.4$ \\
\hline Upper Incisal inclination U1-PL $\left(^{\circ}\right)$ & 112.8 & $98.5-131.7$ & 113.9 & $99.9-137.4$ \\
\hline Lower Incisal inclination $\mathrm{L} 1-\mathrm{MP}\left(^{\circ}\right)$ & 86.7 & $72.7-105.4$ & 88.8 & $75.9-103.5$ \\
\hline
\end{tabular}

Table 5

$\mathrm{P}$ values for the stability between Group A and Group B in anteroposterior (x) and vertical (y) dimensions.

\begin{tabular}{|c|c|c|c|c|c|c|c|c|}
\hline & & & Absolute relapse $\left(\mathrm{mm} /{ }^{\circ}\right)$ & $\mathrm{p}$ value & Sign. & Relative relapse $^{\mathrm{a}}$ & $\mathrm{p}$ value & Sign. \\
\hline \multirow{4}{*}{ A point $(\mathrm{x})(\mathrm{mm})$} & Group A & Mean & -0.64 & 0.95 & NS & -0.40 & 0.51 & NS \\
\hline & & SD & 0.78 & & & 0.78 & & \\
\hline & Group B & Mean & -0.75 & & & -0.42 & & \\
\hline & & SD & 0.73 & & & 1.03 & & \\
\hline \multirow[t]{4}{*}{ PNS (x) (mm) } & Group A & Mean & -0.09 & 0.15 & NS & -0.12 & 0.47 & NS \\
\hline & & SD & 1.18 & & & 0.98 & & \\
\hline & Group B & Mean & -0.54 & & & -0.02 & & \\
\hline & & SD & 0.99 & & & 0.47 & & \\
\hline \multirow[t]{4}{*}{$\mathrm{U}$ tip $(\mathrm{x})(\mathrm{mm})$} & Group A & Mean & -0.27 & 0.70 & NS & -0.09 & 0.86 & NS \\
\hline & & SD & 1.34 & & & 0.70 & & \\
\hline & Group B & Mean & -0.22 & & & -0.19 & & \\
\hline & & SD & 1.31 & & & 1.58 & & \\
\hline \multirow[t]{4}{*}{$\operatorname{SNA}(\mathrm{x})\left(^{\circ}\right)$} & Group A & Mean & -0.57 & 0.44 & NS & -0.33 & 0.39 & NS \\
\hline & & SD & 0.74 & & & 0.56 & & \\
\hline & Group B & Mean & -0.75 & & & -0.07 & & \\
\hline & & SD & 0.82 & & & 0.74 & & \\
\hline \multirow[t]{4}{*}{ U tip (y) (mm) } & Group A & Mean & 1.07 & 0.47 & NS & 0.77 & 0.49 & NS \\
\hline & & SD & 0.95 & & & 0.90 & & \\
\hline & Group B & Mean & 0.82 & & & 0.82 & & \\
\hline & & SD & 0.67 & & & 1.37 & & \\
\hline \multirow[t]{4}{*}{ PNS (y) (mm) } & Group A & Mean & 0.17 & 0.74 & NS & -0.23 & 1.00 & NS \\
\hline & & SD & 0.92 & & & 0.70 & & \\
\hline & Group B & Mean & 0.11 & & & -0.50 & & \\
\hline & & SD & 0.86 & & & 2.42 & & \\
\hline
\end{tabular}

a Calculated as the relative change between the postoperative and follow-up situations in relation to the original transfer. 
Table 6

P values for the stability between Group A and Group B in subgroup 1 in anteroposterior (x) and vertical (y) dimensions.

\begin{tabular}{|c|c|c|c|c|c|c|c|c|}
\hline & & & Absolute relapse $\left(\mathrm{mm} /{ }^{\circ}\right)$ & $\mathrm{p}$ value & Sign. & Relative relapse $^{a}$ & $\mathrm{p}$ value & Sign. \\
\hline \multirow[t]{4}{*}{ A point $(\mathrm{x})(\mathrm{mm})$} & Group A & Mean & -0.64 & 0.83 & NS & -1.03 & 0.83 & NS \\
\hline & & SD & 0.88 & & & 1.29 & & \\
\hline & Group B & Mean & -0.62 & & & -1.47 & & \\
\hline & & SD & 0.62 & & & 2.07 & & \\
\hline \multirow[t]{4}{*}{ PNS (x) (mm) } & Group A & Mean & 0.25 & 0.22 & NS & -0.07 & 0.44 & NS \\
\hline & & SD & 0.75 & & & 1.82 & & \\
\hline & Group B & Mean & -0.16 & & & 0.22 & & \\
\hline & & SD & 0.69 & & & 0.99 & & \\
\hline \multirow[t]{4}{*}{$\mathrm{U} \operatorname{tip}(\mathrm{x})(\mathrm{mm})$} & Group A & Mean & -0.24 & 0.72 & NS & -0.13 & 0.13 & NS \\
\hline & & SD & 1.72 & & & 1.29 & & \\
\hline & Group B & Mean & -0.60 & & & -0.81 & & \\
\hline & & $\mathrm{SD}$ & 1.40 & & & 0.21 & & \\
\hline \multirow[t]{4}{*}{ SNA $(x)\left({ }^{\circ}\right)$} & Group A & Mean & -0.60 & 0.71 & NS & -0.83 & 0.28 & NS \\
\hline & & SD & 0.74 & & & 0.83 & & \\
\hline & Group B & Mean & -0.68 & & & 0.20 & & \\
\hline & & $\mathrm{SD}$ & 0.75 & & & 1.72 & & \\
\hline \multirow[t]{4}{*}{ U tip (y) (mm) } & Group A & Mean & 0.86 & 0.21 & NS & 0.56 & 1.00 & NS \\
\hline & & SD & 0.61 & & & 0.40 & & \\
\hline & Group B & Mean & 1.44 & & & 1.02 & & \\
\hline & & $\mathrm{SD}$ & 0.96 & & & 1.53 & & \\
\hline \multirow[t]{4}{*}{ PNS (y) (mm) } & Group A & Mean & 0.56 & 0.09 & NS & -0.21 & 0.62 & NS \\
\hline & & SD & 1.03 & & & 0.49 & & \\
\hline & Group B & Mean & -0.48 & & & -0.61 & & \\
\hline & & SD & 0.79 & & & 0.56 & & \\
\hline
\end{tabular}

a Calculated as the relative change between the postoperative and follow-up situations in relation to the original transfer.

Table 7

P values for the stability between Group A and Group B in subgroup 2 in anteroposterior (x) and vertical (y) dimensions.

\begin{tabular}{|c|c|c|c|c|c|c|c|c|}
\hline & & & Absolute relapse $\left(\mathrm{mm} /{ }^{\circ}\right)$ & $\mathrm{p}$ value & Sign. & Relative relapse $^{\mathrm{a}}$ & $\mathrm{p}$ value & Sign. \\
\hline \multirow[t]{4}{*}{ A point $(\mathrm{x})(\mathrm{mm})$} & Group A & Mean & -0.67 & 0.99 & NS & -0.17 & 0.50 & NS \\
\hline & & SD & 0.78 & & & 0.19 & & \\
\hline & Group B & Mean & -0.79 & & & -0.15 & & \\
\hline & & SD & 0.76 & & & 0.14 & & \\
\hline \multirow[t]{4}{*}{ PNS (x) (mm) } & Group A & Mean & -0.28 & 0.58 & NS & -0.06 & 0.68 & NS \\
\hline & & SD & 1.28 & & & 0.28 & & \\
\hline & Group B & Mean & -0.53 & & & -0.09 & & \\
\hline & & SD & 0.93 & & & 0.20 & & \\
\hline \multirow[t]{4}{*}{$\mathrm{U}$ tip $(\mathrm{x})(\mathrm{mm})$} & Group A & Mean & -0.36 & 0.34 & NS & -0.08 & 0.25 & NS \\
\hline & & SD & 1.26 & & & 0.24 & & \\
\hline & Group B & Mean & -0.04 & & & 0.01 & & \\
\hline & & SD & 1.16 & & & 0.27 & & \\
\hline \multirow[t]{4}{*}{$\operatorname{SNA}(\mathrm{x})\left({ }^{\circ}\right)$} & Group A & Mean & -0.58 & 0.50 & NS & -0.14 & 0.91 & NS \\
\hline & & SD & 0.78 & & & 0.19 & & \\
\hline & Group B & Mean & -0.76 & & & -0.14 & & \\
\hline & & SD & 0.86 & & & 0.13 & & \\
\hline \multirow[t]{4}{*}{ U tip (y) (mm) } & Group A & Mean & 1.19 & 0.12 & NS & 0.86 & 0.52 & NS \\
\hline & & SD & 1.06 & & & 1.03 & & \\
\hline & Group B & Mean & 0.64 & & & 0.66 & & \\
\hline & & SD & 0.49 & & & 0.95 & & \\
\hline \multirow[t]{4}{*}{ PNS (y) (mm) } & Group A & Mean & -0.06 & 0.35 & NS & -0.14 & 0.91 & NS \\
\hline & & SD & 0.78 & & & 0.63 & & \\
\hline & Group B & Mean & 0.26 & & & -0.73 & & \\
\hline & & $\mathrm{SD}$ & 0.83 & & & 2.30 & & \\
\hline
\end{tabular}

a Calculated as the relative change between the postoperative and follow-up situations in relation to the original transfer.

dimension, taking into account the direction of the original movement of the maxillary segments in the vertical dimension $(\mathrm{p}=0.049)$ (Table 8$)$.

No statistically significant differences were found in subgroup 2.2, as shown in Table 9.

The stability of the $U$ tip was further examined with linear regression analysis. According to the results, the absolute relapse of the $U$ tip point showed a statistically significant difference in the vertical dimension in subgroup 2.1, taking into account the age of the patients during the surgery as well as the original direction of the movement of the maxillary segments $\left(\mathrm{p}=0.0094, \mathrm{R}^{2}\right.$ adjusted $=0.326$, coefficient $\left.=-1.20670\right)$.
Adding the open bite to the regression model, the p-value was even lower ( $\mathrm{p}=0.00867$, coefficient $=-1.187091$ ) and the adjusted $R^{2}$ was a little higher $\left(R^{2}\right.$ adjusted $\left.=0.375\right)$. Adding any other independent variable (sex, rheumatoid disease, smoking, use of bone graft during the operation) to the model neither improved the predictive power of the model nor yielded any statistically significant effect. The models did not suffer from heteroscedasticity, but given the small sample size, it was difficult to determine whether the residuals were normally distributed; the Kolmogorov-Smirnov and Shapiro-Wilk tests indicated normally distributed residuals, but this could not be confirmed by looking at the histograms. 
Table 8

P values for the stability between Group A and Group B in subgroup 2.1 in anteroposterior (x) and vertical (y) dimensions.

\begin{tabular}{|c|c|c|c|c|c|c|c|c|}
\hline & & & Absolute relapse $\left(\mathrm{mm} /{ }^{\circ}\right)$ & $\mathrm{p}$ value & Sign. & Relative relapse $^{\mathrm{a}}$ & $\mathrm{p}$ value & Sign. \\
\hline \multirow[t]{4}{*}{ A point $(\mathrm{x})(\mathrm{mm})$} & Group A & Mean & -0.83 & 0.15 & NS & -0.22 & 0.30 & NS \\
\hline & & SD & 0.74 & & & 0.19 & & \\
\hline & Group B & Mean & -0.56 & & & -0.19 & & \\
\hline & & SD & 0.47 & & & 0.16 & & \\
\hline \multirow[t]{4}{*}{ PNS (x) (mm) } & Group A & Mean & -0.53 & 0.46 & NS & -0.13 & 0.13 & NS \\
\hline & & SD & 1.10 & & & 0.29 & & \\
\hline & Group B & Mean & -0.17 & & & -0.06 & & \\
\hline & & SD & 0.74 & & & 0.25 & & \\
\hline \multirow[t]{4}{*}{$\mathrm{U} \operatorname{tip}(\mathrm{x})(\mathrm{mm})$} & Group A & Mean & -0.81 & 0.50 & NS & -0.17 & 0.81 & NS \\
\hline & & SD & 0.78 & & & 0.21 & & \\
\hline & Group B & Mean & -0.32 & & & -0.10 & & \\
\hline & & SD & 0.97 & & & 0.26 & & \\
\hline \multirow[t]{4}{*}{ SNA $(x)\left({ }^{\circ}\right)$} & Group A & Mean & -0.79 & 0.46 & NS & -0.20 & 0.50 & NS \\
\hline & & SD & 0.76 & & & 0.20 & & \\
\hline & Group B & Mean & -0.49 & & & -0.16 & & \\
\hline & & SD & 0.50 & & & 0.15 & & \\
\hline \multirow[t]{4}{*}{ U tip (y) (mm) } & Group A & Mean & 1.31 & 0.051 & NS & 0.70 & 0.049 & $\mathrm{~S}$ \\
\hline & & SD & 0.79 & & & 0.58 & & \\
\hline & Group B & Mean & 0.66 & & & 0.34 & & \\
\hline & & SD & 0.50 & & & 0.33 & & \\
\hline \multirow[t]{4}{*}{ PNS (y) (mm) } & Group A & Mean & -0.14 & 0.41 & NS & -0.15 & 0.75 & NS \\
\hline & & $\mathrm{SD}$ & 0.77 & & & 0.50 & & \\
\hline & Group B & Mean & 0.40 & & & -1.34 & & \\
\hline & & SD & 1.12 & & & 3.32 & & \\
\hline
\end{tabular}

${ }^{\text {a }}$ Calculated as the relative change between the postoperative and follow-up situations in relation to the original transfer.

Table 9

P values for the stability between Group A and Group B in subgroup 2.2 in anteroposterior (x) and vertical (y) dimensions.

\begin{tabular}{|c|c|c|c|c|c|c|c|c|}
\hline & & & Absolute relapse $\left(\mathrm{mm} /{ }^{\circ}\right)$ & $\mathrm{p}$ value & Sign. & Relative relapse $^{\mathrm{a}}$ & $\mathrm{p}$ value & Sign. \\
\hline \multirow[t]{4}{*}{ A point $(\mathrm{x})(\mathrm{mm})$} & Group A & Mean & -0.40 & 0.22 & NS & -0.07 & 0.52 & NS \\
\hline & & SD & 0.82 & & & 0.15 & & \\
\hline & Group B & Mean & -1.00 & & & -0.11 & & \\
\hline & & SD & 0.93 & & & 0.10 & & \\
\hline \multirow[t]{4}{*}{$\operatorname{PNS}(\mathrm{x})(\mathrm{mm})$} & Group A & Mean & 0.16 & 0.19 & NS & 0.06 & 0.35 & NS \\
\hline & & SD & 1.54 & & & 0.25 & & \\
\hline & Group B & Mean & -0.85 & & & -0.11 & & \\
\hline & & SD & 1.00 & & & 0.15 & & \\
\hline \multirow[t]{4}{*}{$\mathrm{U}$ tip $(\mathrm{x})(\mathrm{mm})$} & Group A & Mean & 0.41 & 0.96 & NS & 0.07 & 0.60 & NS \\
\hline & & SD & 1.60 & & & 0.22 & & \\
\hline & Group B & Mean & 0.22 & & & 0.11 & & \\
\hline & & SD & 1.30 & & & 0.25 & & \\
\hline \multirow[t]{4}{*}{ SNA $(x)\left({ }^{\circ}\right)$} & Group A & Mean & -0.21 & 0.11 & NS & -0.05 & 0.42 & NS \\
\hline & & SD & 0.72 & & & 0.12 & & \\
\hline & Group B & Mean & -1.01 & & & -0.11 & & \\
\hline & & SD & 1.06 & & & 0.12 & & \\
\hline \multirow[t]{4}{*}{ U tip (y) (mm) } & Group A & Mean & 1.00 & 0.88 & NS & 1.15 & 0.52 & NS \\
\hline & & SD & 1.47 & & & 1.55 & & \\
\hline & Group B & Mean & 0.63 & & & 0.95 & & \\
\hline & & SD & 0.51 & & & 1.23 & & \\
\hline \multirow[t]{4}{*}{ PNS (y) (mm) } & Group A & Mean & 0.09 & 0.96 & NS & -0.13 & 0.42 & NS \\
\hline & & SD & 0.84 & & & 0.86 & & \\
\hline & Group B & Mean & 0.13 & & & -0.19 & & \\
\hline & & SD & 0.47 & & & 0.28 & & \\
\hline
\end{tabular}

a Calculated as the relative change between the postoperative and follow-up situations in relation to the original transfer.

Other models of the regression analysis showed no statistically significant differences between the stability of the maxillary segments, depending on the fixation plate used.

The intra-rater reliability was calculated to three points of interest: A point, PNS point and $U$ tip point, both in anteroposterior $(\mathrm{X})$ and vertical $(\mathrm{Y})$ dimensions. The results are shown in Table 10.

\section{Discussion}

Three-dimensional planning and PSIs are interesting modern tools for planning, repositioning and fixation in Le Fort I osteotomy (Van Hemelen et al., 2015; Suojanen et al., 2016; Heufelder et al., 2017). According to the literature, the fitting of PSIs is accurate and the postoperative results are predictable and reliable (Heufelder et al., 2017). We demonstrated earlier that the use of PSIs may reduce the need for reoperations due to insufficient advancement of the maxillary segments immediately after surgery (Suojanen et al., 2018). In that study 0 out of 31 maxillae fixed with PSIs needed immediate reoperations due to malocclusion whereas 3 out of 37 mini-plate fixed maxillae were reoperated. However, the difference was not statistically significant. Immediate reoperation due to malocclusion almost solely relates to immediate bony relapse due to tension during osteosynthesis. It is possible that one reason for reoperation was related to mini-plate fixation. However, the effect of other reasons cannot be excluded. The small sample size of the study is also a restrictive factor when drawing 
Table 10

The intra-class correlation coefficient (ICC) values for the points of interest in anteroposterior $(\mathrm{X})$ and vertical $(\mathrm{Y})$ dimensions to determine the intra-examiner reliability.

\begin{tabular}{lll}
\hline & ICC & \\
\cline { 2 - 3 } & $\mathrm{X}$ & $\mathrm{Y}$ \\
\hline A point & 0.98 & 0.965 \\
PNS & 0.984 & 0.991 \\
U tip & 0.999 & 1.000 \\
\hline
\end{tabular}

conclusions from the study. Because the patients were reoperated shortly after the original surgery, there is no follow-up radiograph (T3) available of the original surgery. This leads to negative sampling bias in the mini-plate group.

The aim of our study was to evaluate differences in the postoperative skeletal stability between Le Fort I osteotomies fixed either by PSIs or by conventional mini-plates. To our knowledge, no similar studies on postoperative skeletal stability comparing fixation with PSIs and mini-plates have been reported earlier.

All patients in our study underwent a Le Fort I osteotomy, performed with a similar surgical protocol regardless of the fixation system used. Four senior surgeons were in charge of the operations, but this study did not investigate the differences between the surgeons.

From the initial patient data, 14 patients were excluded from the study due to lack of radiographs. The lacking radiographs were most often the follow-up radiographs, which may indicate that these were patients who did not suffer from any kind of postoperative complications or problems. Thus, the group of patients included in this study may consist of patients who had more postoperative problems or complications than the patients on average.

When analysing skeletal stability, the difficulty in comparing serial cephalometric radiographs must be remembered. During the cephalometric tracing, it was noted, for example, that the anterior nasal spine (ANS) point was difficult to trace or untraceable in many of the postoperative and follow-up radiographs due to remodelling during the surgery. Hence, this point was not used in the evaluation of the relapse.

Nine of the Le Fort I osteotomies were performed with segmentation of the maxillary segments into two pieces and two into three pieces. Because the sample size was so small, analysing the effects of segmentation on postoperative skeletal stability was not possible. Larger clinical studies are warranted for investigating the possible differences of the segmentations.

Twenty-seven patients underwent a BSSO in addition to the Le Fort I osteotomy. Earlier studies (Tate et al., 1994) have shown a statistically significant reduction in voluntary bite forces in patients treated for mandibular angle fractures. Although Tate et al. investigated patients suffering from a mandibular fracture, the clinical situation is quite similar after a BSSO performed for orthognathic reasons. Hence, a mandibular BSSO combined with a Le Fort I osteotomy can reduce the maximum bite forces postoperatively for several weeks and thus have a stabilizing effect on the maxillary segments as compared to the cases of only a maxillary Le Fort I osteotomy. However, according to our analysis, there was no statistical difference between the number of bimaxillary surgeries in Group A and Group B.

Analysing the data, the results of postoperative skeletal stability revealed that relapse may seem exceptionally large when only a small transfer of the maxillary segments in the anteroposterior dimension was performed. These are usually cases in which the main purpose of the surgery was to rotate the maxillary segments vertically either clockwise or counter-clockwise to correct malocclusion. In these cases, the A point was only moved minimally in the anteroposterior dimension as a result of the rotational movement of the maxillary segments. For the limited accuracy of the cephalometric tracing as well as for the remodelling and resorption of the bone, relapse may seem as large as $100 \%$ or even more in these situations. This is due to remodelling of the sub-spinal area already during surgery to ensure that there will not be any interference between the septum and the floor of the nasal cavity leading to septum deviation, especially in counter-clockwise repositioning of the maxillary segments. For this reason, the A point was only used in the evaluation of the relapse in the anteroposterior dimension. Similar difficulties in identifying ANS and A points have been reported by earlier investigators (Venkategowda et al., 2017). The rationale and the effect of sub-spinal osteotomy on soft-tissue changes in the nasal area were analysed earlier (Mommaerts et al., 2000) but to our knowledge no comparative analysis of conventional Le Fort I osteotomy exists. However, because the nasal spine is surgically separated from the maxillary segment, and sometimes even partly resected during the impaction, it is possible that the remodelling of this area may vary considerably from one patient to another.

With regard to the postoperative skeletal stability of the maxillae, no statistically significant difference was found between the PSI or mini-plate fixed maxillae when examining the whole group of patients. A statistically significant difference was found in the relative relapse of the $U$ tip in the vertical dimension in subgroup 2.1. The result suggests better stability for the miniplate fixed maxillae than for the PSI fixed maxillae with small advancements. However, after multiple testing correction, this pvalue was also greater than 0.05 ; thus, no reliable conclusions could be derived on the basis of the analysis. Interestingly, the same statistically significant difference was not found in the relative relapse of the $U$ tip in the vertical dimension in subgroup 2.2 , that is, the forward movement of the A point more than $5 \mathrm{~mm}$. Neither did the whole subgroup 2 (forward movement of the A point more than $2 \mathrm{~mm}$ ) show statistically significant difference in the relapse of the $U$ tip in the vertical dimension. Because subgroup 2 consisted of only 38 patients, of whom 21 belonged to subgroup 2.1 and 17 to subgroup 2.2, these divergent findings are most likely due to small sample size, and more investigations are needed to confirm the findings.

The stability of the $U$ tip was further examined with linear regression analysis. According to the results, the absolute relapse of the $U$ tip point showed statistically significant difference in the vertical dimension in subgroup 2.1. However, when taking into account the small sample size of only 12 patients in Group A and nine patients in Group B, only directional conclusions about the better stability of the mini-plate fixed maxillae can be drawn, based on this study, and further investigations are needed to confirm this preliminary result. It is also possible for patients with mini-plate surgery with bony interference or plate tension (and susceptibility to relapse) postoperatively to need early reoperations, which may distort the findings.

The intra-rater reliability was calculated to three points of interest: A point, PNS point and U tip point, both in anteroposterior $(\mathrm{X})$ and vertical $(\mathrm{Y})$ dimensions. The intra-class correlation values were in general excellent, the vertical A point being the weakest $($ ICC $=0.965)$. This result was already predicted at an early stage of the study, because the curve of the anterior maxilla may be very broad, thus causing large variations in determining the position of the $A$ point in the vertical dimension. Also, it must be noted that all patients were operated on with a sub-spinal Le Fort I osteotomy, in which the nasal spine was also separated from the maxillary 
segments; this causes some remodelling during the healing period, which may to some extent also affect the reliability of the A point determination in cephalometric radiographs. This may also affect the interpretation, especially in small advancements. For this reason, the A point was only used in the determination of relapse in the anteroposterior direction. Other values of ICC showed excellent accuracy.

\section{Conclusions}

According to the results, the choice between the two fixation methods did not seem to affect the postoperative skeletal stability of the maxillae. Although a statistically significant difference was found in the vertical stability of the $U$ tip in one of the subgroups, $U$ tip is a dental point and does not directly correlate to the skeletal stability. For this reason, future prospective studies are warranted to confirm the results. For example, 3D imaging and 3D fusion analysis of different time points (T1, T2, T3) would be advantageous and would allow analysis of 3D spatial changes.

\section{Funding}

This work was supported by the Emil Aaltonen Foundation, the Finnish Women Dentists' Association, the Finnish-Norwegian Medical Foundation, the Finnish Medical Foundation, the Paulo Foundation, and Helsinki University Hospital funds.

\section{Declaration of interest}

Authors JS, JL and PS have participated in congresses where attendance fees were in part or in total supported by DePuySynthes or KLS-Martin.

\section{Acknowledgements}

The authors would like to thank biostatisticians Paula Bergman and Anna But in the Biostatistics Consulting Department of the University of Helsinki for providing statistical help.

Appendix A. Table A.1. Patient characteristics.

\begin{tabular}{|c|c|c|c|c|c|c|c|c|c|}
\hline Patient no. & Group & Sub-group & $\operatorname{Sex}(F / M)$ & Age (y) & Orthodontic diagnosis & Type of surgery & One-piece/segment & Movement of maxilla & Bone graft \\
\hline 1 & A & 1 & M & 25.4 & $\begin{array}{l}\text { Open bite, cross bite, maxillary } \\
\text { retrognathia }\end{array}$ & Le Fort I & Two-piece & Straight & No \\
\hline 2 & A & 2.1 & M & 25.6 & $\begin{array}{l}\text { Cross bite, mandibular } \\
\text { prognathia, maxillary } \\
\text { retrognathia, asymmetry }\end{array}$ & Le Fort I & One-piece & Straight & No \\
\hline 3 & A & 1 & $\mathrm{~F}$ & 44.2 & $\begin{array}{l}\text { Open bite, mandibular } \\
\text { retrognathia }\end{array}$ & Bimaxillary & One-piece & $\mathrm{CCW}$ & DBX to maxillae \\
\hline 4 & A & 2.2 & M & 28.3 & $\begin{array}{l}\text { Cross bite, maxillary } \\
\text { retrognathia, asymmetry }\end{array}$ & Le Fort I & One-piece & Straight & No \\
\hline 5 & A & 2.1 & $\mathrm{~F}$ & 22.3 & $\begin{array}{l}\text { Open bite, mandibular } \\
\text { retrognathia, asymmetry, } \\
\text { crowding }\end{array}$ & Bimaxillary & One-piece & Straight & $\begin{array}{l}\text { DBX to maxillae } \\
\text { and mandible }\end{array}$ \\
\hline 6 & A & 2.2 & M & 25.0 & $\begin{array}{l}\text { Open bite, cross bite, } \\
\text { mandibular prognathia, } \\
\text { asymmetry }\end{array}$ & Bimaxillary & Two-piece & $\mathrm{CW}$ & DBX to maxillae \\
\hline 7 & A & 2.2 & $\mathrm{~F}$ & 24.3 & $\begin{array}{l}\text { Cross bite, maxillary } \\
\text { retrognathia }\end{array}$ & Le Fort I & One-piece & Straight & DBX \\
\hline 8 & A & 1 & $\mathrm{~F}$ & 48.5 & $\begin{array}{l}\text { Cross bite, maxillary } \\
\text { retrognathia, asymmetry, } \\
\text { crowding }\end{array}$ & Le Fort I & Two-piece & Straight & DBX \\
\hline 9 & A & 1 & M & 33.2 & $\begin{array}{l}\text { Cross bite, mandibular } \\
\text { prognathia, asymmetry }\end{array}$ & Bimaxillary & Two-piece & Straight & BioOss \\
\hline 10 & A & 2.1 & M & 24.4 & $\begin{array}{l}\text { Mandibular prognathia, } \\
\text { maxillary retrognathia, } \\
\text { hypodontia }\end{array}$ & Le Fort I & One-piece & Straight & Chronos \\
\hline 11 & A & 2.1 & $\mathrm{~F}$ & 19.4 & $\begin{array}{l}\text { Open bite, mandibular } \\
\text { retrognathia }\end{array}$ & Bimaxillary & One-piece & Straight & No \\
\hline 12 & A & 2.2 & $\mathrm{~F}$ & 43.3 & $\begin{array}{l}\text { Cross bite, maxillary } \\
\text { retrognathia, asymmetry }\end{array}$ & Le Fort I & Two-piece & Straight & $\begin{array}{l}\text { Human bone and } \\
\text { DBX }\end{array}$ \\
\hline 13 & A & 1 & $\mathrm{~F}$ & 23.6 & $\begin{array}{l}\text { Open bite, mandibular } \\
\text { retrognathia }\end{array}$ & Bimaxillary & One-piece & CCW & Human bone \\
\hline 14 & A & 2.2 & $\mathrm{~F}$ & 27.1 & $\begin{array}{l}\text { Open bite, mandibular } \\
\text { retrognathia }\end{array}$ & Bimaxillary & One-piece & CCW & No \\
\hline 15 & A & 2.1 & $\mathrm{~F}$ & 37.0 & $\begin{array}{l}\text { Open bite, mandibular } \\
\text { retrognathia }\end{array}$ & Bimaxillary & One-piece & Straight & BonAlive to mandible \\
\hline 16 & A & 2.1 & $\mathrm{~F}$ & 29.7 & Open bite, asymmetry & Bimaxillary & One-piece & Straight & No \\
\hline 17 & A & 2.1 & $\mathrm{~F}$ & 45.6 & $\begin{array}{l}\text { Cross bite, maxillary } \\
\text { retrognathia }\end{array}$ & Le Fort I & One-piece & CW & No \\
\hline 18 & A & 1 & M & 27.3 & Open bite, cross bite & Bimaxillary & Two-piece & $\mathrm{CW}$ & No \\
\hline 19 & A & 2.2 & M & 21.4 & $\begin{array}{l}\text { Open bite, mandibular } \\
\text { prognathia }\end{array}$ & Bimaxillary & One-piece & $\mathrm{CW}$ & $\begin{array}{l}\text { Human bone to } \\
\text { maxillae }\end{array}$ \\
\hline 20 & A & 2.1 & $\mathrm{~F}$ & 21.4 & Open bite, cross bite & Bimaxillary & One-piece & CCW & No \\
\hline 21 & A & 2.1 & M & 23.9 & Open bite, cross bite, crowding & Le Fort I & One-piece & CW & BioOss \\
\hline 22 & A & 2.2 & $\mathrm{~F}$ & 25.3 & $\begin{array}{l}\text { Mandibular prognathia, } \\
\text { maxillary retrognathia }\end{array}$ & Le Fort I & One-piece & $\mathrm{CW}$ & BioOss \\
\hline 23 & A & 2.1 & M & 37.4 & $\begin{array}{l}\text { Acromegaly, open bite, cross } \\
\text { bite, mandibular macrognathia, } \\
\text { asymmetry }\end{array}$ & Bimaxillary & One-piece & Straight & Iliac crest to maxillae \\
\hline
\end{tabular}




\begin{tabular}{|c|c|c|c|c|c|c|c|c|c|}
\hline Patient no. & Group & Sub-group & $\operatorname{Sex}(F / M)$ & Age (y) & Orthodontic diagnosis & Type of surgery & One-piece/segment & Movement of maxilla & Bone graft \\
\hline 24 & A & 2.1 & $\mathrm{~F}$ & 25.9 & $\begin{array}{l}\text { Cross bite, deep bite, } \\
\text { mandibular retrognathia }\end{array}$ & Bimaxillary & Two-piece & Straight & BonAlive to mandible \\
\hline 25 & A & 2.1 & $\mathrm{~F}$ & 20.4 & $\begin{array}{l}\text { Open bite, mandibular } \\
\text { retrognathia }\end{array}$ & Bimaxillary & One-piece & $\mathrm{CCW}$ & No \\
\hline 26 & A & 1 & $\mathrm{~F}$ & 25.3 & $\begin{array}{l}\text { Open bite, cross bite, maxillary } \\
\text { retrognathia, mandibular } \\
\text { retrognathia, crowding }\end{array}$ & Bimaxillary & Two-piece & $\mathrm{CCW}$ & BonAlive to mandible \\
\hline 27 & A & 1 & M & 25.2 & Open bite, hypodontia & Bimaxillary & Three-piece & Straight & BioOss to mandible \\
\hline 28 & B & 2.2 & M & 25.8 & $\begin{array}{l}\text { Open bite, cross bite, } \\
\text { mandibular prognathia, } \\
\text { maxillary retrognathia, } \\
\text { hypodontia }\end{array}$ & Bimaxillary & One-piece & Straight & Iliac crest to maxillae \\
\hline 29 & B & 2.2 & M & 24.0 & $\begin{array}{l}\text { Cross bite, mandibular } \\
\text { prognathia, maxillary } \\
\text { retrognathia }\end{array}$ & Le Fort I & Two-piece & CCW & Iliac crest \\
\hline 30 & B & 2.1 & $\mathrm{~F}$ & 19.6 & Open bite, crowding & Bimaxillary & One-piece & Straight & BonAlive to mandible \\
\hline 31 & B & 2.1 & M & 36.9 & $\begin{array}{l}\text { Open bite, cross bite, } \\
\text { mandibular retrognathia }\end{array}$ & Bimaxillary & One-piece & $\mathrm{CCW}$ & BonAlive to mandible \\
\hline 32 & $\mathrm{~B}$ & 2.2 & M & 27.0 & $\begin{array}{l}\text { Cross bite, mandibular } \\
\text { prognathia, maxillary } \\
\text { retrognathia, crowding }\end{array}$ & Le Fort I & One-piece & Straight & Iliac crest \\
\hline 33 & B & 2.2 & M & 52.0 & $\begin{array}{l}\text { Acromegaly, open bite, cross } \\
\text { bite, mandibular macrognathia, } \\
\text { asymmetry }\end{array}$ & Le Fort I & One-piece & $\mathrm{CCW}$ & Iliac crest \\
\hline 34 & B & 2.2 & $\mathrm{~F}$ & 28.1 & $\begin{array}{l}\text { Cross bite, mandibular } \\
\text { prognathia, maxillary } \\
\text { retrognathia }\end{array}$ & Le Fort I & Three-piece & Straight & No \\
\hline 35 & $\mathrm{~B}$ & 2.2 & $\mathrm{~F}$ & 23.1 & $\begin{array}{l}\text { Cross bite, maxillary } \\
\text { retrognathia, asymmetry, } \\
\text { crowding }\end{array}$ & Le Fort I & One-piece & $\mathrm{CW}$ & DBX \\
\hline 36 & B & 2.1 & $\mathrm{~F}$ & 33.5 & $\begin{array}{l}\text { Cross bite, mandibular } \\
\text { prognathia, maxillary } \\
\text { retrognathia }\end{array}$ & Le Fort I & One-piece & $\mathrm{CW}$ & DBX \\
\hline 37 & $\mathrm{~B}$ & 2.1 & $\mathrm{~F}$ & 24.4 & $\begin{array}{l}\text { Open bite, mandibular } \\
\text { retrognathia }\end{array}$ & Bimaxillary & One-piece & Straight & BonAlive to mandible \\
\hline 38 & B & 1 & $\mathrm{~F}$ & 24.6 & Open bite, cross bite & Le Fort I & One-piece & CW & DBX \\
\hline 39 & B & 2.2 & M & 27.1 & $\begin{array}{l}\text { Cross bite, mandibular } \\
\text { prognathia, maxillary } \\
\text { retrognathia, asymmetry, } \\
\text { crowding }\end{array}$ & Le Fort I & One-piece & Straight & Iliac crest \\
\hline 40 & B & 1 & M & 22.2 & $\begin{array}{l}\text { Open bite, mandibular } \\
\text { retrognathia }\end{array}$ & Bimaxillary & One-piece & $\mathrm{CCW}$ & No \\
\hline 41 & B & 2.1 & $\mathrm{~F}$ & 48.7 & $\begin{array}{l}\text { Cross bite, mandibular } \\
\text { prognathia }\end{array}$ & Le Fort I & One-piece & Straight & No \\
\hline 42 & B & 2.2 & M & 22.9 & $\begin{array}{l}\text { Open bite, maxillary } \\
\text { retrognathia }\end{array}$ & Bimaxillary & One-piece & Straight & Iliac crest \\
\hline 43 & B & 2.1 & $\mathrm{~F}$ & 21.8 & $\begin{array}{l}\text { Open bite, mandibular } \\
\text { retrognathia, crowding }\end{array}$ & Bimaxillary & One-piece & $\mathrm{CW}$ & No \\
\hline 44 & B & 2.2 & M & 45.1 & $\begin{array}{l}\text { Cross bite, mandibular } \\
\text { prognathia, maxillary } \\
\text { retrognathia }\end{array}$ & Bimaxillary & One-piece & $\mathrm{CW}$ & Iliac crest \\
\hline 45 & B & 2.2 & $\mathrm{~F}$ & 21.3 & $\begin{array}{l}\text { Cross bite, mandibular } \\
\text { prognathia }\end{array}$ & Le Fort I & One-piece & Straight & Human bone \\
\hline 46 & B & 1 & M & 26.1 & $\begin{array}{l}\text { Open bite, maxillary } \\
\text { retrognathia, crowding }\end{array}$ & Le Fort I & One-piece & Straight & No \\
\hline 47 & B & 1 & $\mathrm{~F}$ & 26.9 & Open bite, cross bite, crowding & Le Fort I & One-piece & $\mathrm{CW}$ & No \\
\hline 48 & $\mathrm{~B}$ & 2.1 & M & 23.1 & $\begin{array}{l}\text { Open bite, cross bite, maxillary } \\
\text { retrognathia }\end{array}$ & Le Fort I & One-piece & Straight & Human bone \\
\hline 49 & B & 2.1 & M & 26.3 & $\begin{array}{l}\text { Cross bite, mandibular } \\
\text { prognathia, maxillary } \\
\text { retrognathia, hypodontia }\end{array}$ & Le Fort I & One-piece & Straight & No \\
\hline 50 & $\mathrm{~B}$ & 2.1 & $\mathrm{~F}$ & 22.9 & $\begin{array}{l}\text { Open bite, mandibular } \\
\text { retrognathia, crowding }\end{array}$ & Bimaxillary & One-piece & $\mathrm{CCW}$ & No \\
\hline 51 & $\mathrm{~B}$ & 1 & M & 43.6 & Deep bite & Bimaxillary & One-piece & Straight & Iliac crest to maxillae \\
\hline
\end{tabular}

\section{References}

Epker B: Modifications in the sagittal osteotomy of the mandible. J Oral Surg 35: 157-159, 1977

Gander T, Bredell M, Eliades T, Rucker M, Essig H: Splintless orthognathic surgery: a novel technique using patient-specific implants (PSI). J Craniomaxillofac Surg: 319-322, https://doi.org/10.1016/j.jcms.2014.12.003; 2015

Heufelder M, Wilde F, Pietzka S, Mascha F, Winter K, Schramm A, et al: Clinical accuracy of waferless maxillary positioning using customized surgical guides and patient specific osteosynthesis in bimaxillary orthognathic surgery. J Craniomaxillofac Surg: 1578-1585, https://doi.org/10.1016/j.jcms.2017.06.027; 2017

Larsen AJ, Van Sickels JE, Thrash WJ: Postsurgical maxillary movement: a comparison study of bone plate and screw versus wireosseous fixation. Am J Orthod Dentofacial Orthop 95: 334-343, 1989

Mazzoni S, Bianchi A, Schiariti G, Badiali G, Marchetti C: Computer-aided design and computer-aided manufacturing cutting guides and customized titanium plates are useful in upper maxilla waferless repositioning. J Oral Maxillofac Surg: 701-707, https://doi.org/10.1016/j.joms.2014.10.028; 2015 
Mommaerts MY, Abeloos JV, De Clercq CA, Neyt LF: The effect of the subspinal Le Fort I-type osteotomy on interalar rim width. Int J Adult Orthodon Orthognath Surg 12: 95-100, 1997

Mommaerts MY, Lippens F, Abeloos JV, Neyt LF: Nasal profile changes after maxillary impaction and advancement surgery. J Oral Maxillofac Surg 58: 470-475, 2000 discussion 475-476

Ohba S, Nakao N, Nakatani Y, Yoshimura H, Minamizato T, Kawasaki T, et al: Effects of vertical movement of the anterior nasal spine on the maxillary stability after Le Fort I osteotomy for pitch correction. J Craniofac Surg 26: e481-e485, 2015

Reyneke JP, Bryant RS, Suuronen R, Becker PJ: Postoperative skeletal stability following clockwise and counter-clockwise rotation of the maxillomandibular complex compared to conventional orthognathic treatment. Br J Oral Maxillofac Surg: 56-64, https://doi.org/10.1016/j.bjoms.2005.12.015; 2007

Suojanen J, Leikola J, Stoor P: The use of patient specific implants in ortognatic surgery - a series of 32 maxillary osteotomy patients. J Craniomaxillofac Surg: 1913-1916, https://doi.org/10.1016/j.jcms.2016.09.008; 2016
Suojanen J, Järvinen S, Kotaniemi KV, Reunanen J, Palotie T, Stoor P, et al: Comparison between patient specific implants and conventional mini-plates in Le Fort I osteotomy with regard to infections: No differences in up to 3-year follow-up. J Craniomaxillofac Surg: 1814-1817, https://doi.org/10.1016/j.jcms. 2018.07.011; 2018

Tate GS, Ellis 3rd E, Throckmorton G: Bite forces in patients treated for mandibula angle fractures: implications for fixation recommendations. J Oral Maxillofac Surg 52: 734-736, 1994

Van Hemelen G, Van Genechten M, Renier L, Desmedt M, Verbruggen E, Nadjmi N: Three-dimensional virtual planning in orthognathic surgery enhances the ac curacy of soft tissue prediction. J Craniomaxillofac Surg 43: 918-925, 2015

Venkategowda PR, Prakash AT, Roy ET, Shetty KS, Thakkar S, Maurya R: Stability of vertical, horizontal and angular parameters following superior repositioning of maxilla by Le Fort I osteotomy: a cephalometric study. J Clin Diagn Res 11: ZC10-ZC14, 2017 